\title{
Modeling work of the dispatching service of high-rise building as queuing system
}

\author{
Marina Dement'eva ${ }^{1 *}$, and Anastasiya Dement'eva ${ }^{1}$ \\ ${ }^{1}$ Moscow State University of Civil Engineering, Yaroslavskoe shosse, 26, Moscow, 129337, Russia
}

\begin{abstract}
The article presents the results of calculating the performance indicators of the dispatcher service of a high-rise building as a queuing system with an unlimited queue. The calculation was carried out for three models: with a single control room and brigade of service, with a single control room and a specialized service, with several dispatch centers and specialized services. The aim of the work was to investigate the influence of the structural scheme of the organization of the dispatcher service of a high-rise building on the amount of operating costs and the time of processing and fulfilling applications. The problems of high-rise construction and their impact on the complication of exploitation are analyzed. The composition of exploitation activities of high-rise buildings is analyzed. The relevance of the study is justified by the need to review the role of dispatch services in the structure of management of the quality of buildings. Dispatching service from the lower level of management of individual engineering systems becomes the main link in the centralized automated management of the exploitation of high-rise buildings. With the transition to market relations, the criterion of profitability at the organization of the dispatching service becomes one of the main parameters of the effectiveness of its work. A mathematical model for assessing the efficiency of the dispatching service on a set of quality of service indicators is proposed. The structure of operating costs is presented. The algorithm of decision-making is given when choosing the optimal structural scheme of the dispatching service of a high-rise building.
\end{abstract}

\section{Introduction}

High-rise buildings have become a common phenomenon in the world practice of construction. They are a factor of scientific and technological progress, an indicator of the economic power of the state, determine the prestige of large construction holdings and management companies. Modern cities need renovation. The construction of high-rise buildings solves the problems of the development of territories, raises the diversity of the urban environment, improves the usability. The planning solutions of high-rise buildings are both highly specialized and multifunctional, ideally representing the so-called "city in the city" mode [1-4]. This approach allows us to realize the greatest number of functions in

\footnotetext{
${ }^{*}$ Corresponding author: $\underline{7 d e m @ \text { mail.ru }}$
} 
one construction site and the most economical and ergonomic use of urban space. The Shanghai Center (China), Time Warner Center in Manhattan (New York, USA), MoscowCity (Russia) [5] can serve as vivid examples of such objects.

However, high-rise construction has also negative aspects: the complication of architectural, planning and constructive solutions; more energy consumption, more complicated engineering systems, difficulties in evacuating people, environmental problems due to high density of construction, transport and population [6-9]. The multi functionality of high-rise buildings leads to additional problems: the complexity of the distribution of human flows, the construction of independent engineering systems increases the number of equipment serviced, the uneven use of equipment during the day complicates its management. Despite the fact that the listed problems are solved at the design stage, the complexity of the object leads to the complexity of its further operation. Failures of systems, equipment, structures of high-rise buildings can have more catastrophic consequences, which justifies the increased requirements to the quality of work of managers and exploitation organizations.

Studies show that, according to regulatory requirements [10], the composition of exploitation activities of high-rise buildings is similar to the exploitation of mass-building buildings and includes:

- management of facilities (organization of operation, relationships with related organizations and suppliers, all types of work with tenants and tenants);

- maintenance and repair of building structures and engineering systems of facilities (inspections, monitoring, preparation for seasonal operation, current and major repairs);

- sanitary maintenance (cleaning of common areas, cleaning of houses, care of green areas).

From the point of view of organizing the exploitation of any building, all the works can be divided into two groups according to the volumes, types and terms of implementation: permanent and probabilistic. Permanent works include the sanitary maintenance of buildings and territories, maintenance, scheduled maintenance, technical inspections. Since the types and terms of these works are determined by regulatory documents, and their volumes depend on the building parameters, the structural diagram of the management and operational service makes it possible to determine the relationship between the units, the area of responsibility of each employee and thereby ensure the requirements for the quality of operation. Probabilistic work can occur at random times, because they are emergency. Consequently, the time, volume and nature of probabilistic works are not defined. Only on the basis of a long collection of information on failure statistics can a different degree of probability be judged on the possibility of an accident. For example, the probability of failure of the wall panel is much lower than the failure of the tap in the water supply system. The refusal in the hot water supply system is higher than in the cold water supply system. The presence of probabilistic works complicates the maintenance and requires the optimization of the structural scheme of the managing organization on the basis of the theory of mass service [11-21].

Traditionally, to monitor the reliability and safety of the functioning of the building, timely detection and elimination of emergency situations, the dispatching service integrated into the united dispatching service of the district and the city is provided. However, highrise buildings are unique objects that require specialized work. Consequently, the dispatch service should be part of the structure of the management company serving the high-rise building. At present, the dispatching service of high-rise complexes is a centralized point of automated operation control, using its own specialized software. Consequently, this subdivision from the from auxiliary passes into the category of primary, without which it is impossible to effectively manage the infrastructure of a high-rise building. 
The increase in the number of assigned functions complicates the structure of the dispatching service, which entails the problem of reducing the quality of its work [22-27]. The purpose of the work is to develop an algorithm for making decisions on the selection of the optimal structural scheme of the dispatching service of a high-rise building, taking into account the minimization of operating costs and costs for the maintenance of the dispatching service, and also minimizing processing time and fulfilling orders. To solve the set goal, the following tasks were solved:

- analysis of the cost structure in the modeling of various schemes for organizing the work of the dispatching service;

- analysis of the structure of applications entering the dispatch service at failures of engineering system elements in various functional segments of a high-rise building;

- calculation of the performance indicators of the dispatching service as a queuing system.

\section{Materials and Methods}

The object of research in this article is the organization of the work of the dispatcher service of a high-rise building as a queuing system. The subject of the study is the application of queuing theory in the modeling of various schemes for organizing the work of the dispatching service of a multi-purpose high-rise building and assessing the change in the parameters of its performance.

Statistical analysis of data on failures, functional-cost analysis of operating costs, and system analysis were used to analyze and summarize the data. The performance indicators of the dispatching service were determined on the basis of queuing theory.

Since the design standards in Russia are oriented to the height of buildings up to $75 \mathrm{~m}$, the trend has been to refer objects to high-rise buildings above $75 \mathrm{~m}$. The paper considers a 25 -storey building with a maximum mark of the parapet of the roof of $83.5 \mathrm{~m}$, built in 2008. The building has a zone of apartments, office space, hotel, underground parking. The area of the functional area of the apartments is $40000 \mathrm{~m}^{2}$, office and hotel complex is 45000 $\mathrm{m}^{2}$.

The quality of the work of the dispatching service as a single control center for the operation of a high-rise building can be estimated by the following quantitative indicators:

1. The average number of detected defects during regular inspections - characterizes the quality of monitoring, the qualification of personnel.

2. The average idle time of engineering systems and building elements in anticipation of maintenance and in the process of maintenance - characterizes the operational efficiency of the operation service.

3 . The coefficient of use of working time as a ratio of the average time of employment of workers to the total time for performing operations for the technical operation of the building.

4. Economic exploitation - the expedient use of material and labor resources.

5. The number of justified complaints of the population on the quality of work, the operational efficiency of the units - characterizes the creation of maximum amenities for the residents.

6. The probability of failure-free operation for a specific time interval and the duration of operation of the elements between failures - characterizes operational reliability.

It is impossible to assess the effectiveness of the organization of the work of the dispatching service for any one of the listed indicators, since the values of other indicators may be inadmissible with the best value of one indicator. For example, low material and labor costs may result from a low level of organization of operation, which may be the cause of unacceptable operational efficiency. Therefore, in the practice of operation, it is 
advisable to apply the following approach to the assessment of the dispatching service: the main indicator of the efficiency of management of the exploitation process is adopted, for it the extreme value is determined. The remaining indicators impose restrictions, determined by the standards, technological features, market conditions. As indicators of efficiency, it is advisable to take the profit of the management company and the time for performing repair work with the constraint imposed. Then the mathematical model for assessing the efficiency of the dispatching service can be presented in the following form:

$$
\left\{\begin{array}{l}
S_{p r}=P\left(S_{i n} ; S_{\cos t}\right) \rightarrow \max \\
Z_{\text {sist }}=P\left(Z_{q} ; Z_{\text {serv }}\right) \rightarrow \beta
\end{array}\right.
$$

Where $\mathrm{S}_{\mathrm{pr}}$ - profit in the course of work on troubleshooting; $\mathrm{S}_{\text {in }}$ - income from the activities of dispatching services; $S_{\text {cost }}$ - expenditure from the activity of the dispatching service; $Z_{\text {sist }}-$ the processing time of the application (being in the system); $\mathrm{Z}_{\mathrm{q}}$ the time that the application is waiting for service (waiting in line); $Z_{\text {serv }}$ - time of the application by the technical specialist (being in service); $\mathrm{P}$ - the likelihood that service performance indicators will not exceed the allowable value; $\beta$ - the restriction imposed on the time indicator equal to the duration of the shift.

The average work time can be determined as follows:

$$
Z_{\text {sist }}=Z_{q}+k \cdot\left(Z_{e l}+Z_{m}+Z_{w}\right)
$$

Where $Z_{\mathrm{el}}$ - time of movement in special equipment (movement in the elevator); $Z_{\mathrm{m}}$ - travel time without special equipment; $Z_{\mathrm{w}}$ - time of work execution; $\mathrm{k}$ - time loss factor for technical and technological breaks (receipt and storage of materials, elimination of several faults in one application, etc.).

The average profit from troubleshooting activities can be determined as follows:

$$
S_{p r}=S_{i n} \cdot\left(1-P_{0}\right) \cdot \lambda-\left[S_{m} \cdot\left(1-P_{0}\right) \cdot \lambda+S_{d}+S_{w}+S_{q} \cdot Z_{q} \cdot n_{q}+S_{i d} \cdot P_{0} \cdot \lambda\right]
$$

Where $\mathrm{P}_{0}$ - probability of idle technical personnel; $\lambda$ - the intensity of incoming applications from the dispatcher to the technical staff; $\mathrm{S}_{\mathrm{m}}-$ cost of materials for troubleshooting; $\mathrm{S}_{\mathrm{d}}-$ the cost of organization and maintenance of the dispatching service (personnel costs, rent, communication services, depreciation of fixed assets, software, consumables, etc.); $\mathrm{S}_{\mathrm{w}}$ - the cost of the organization and maintenance of repair teams; $\mathrm{S}_{\mathrm{q}}$ - cost of costs when the application is in the queue (for example, due to loss of resources in the event of an accident); $\mathrm{n}_{\mathrm{q}}$ - average number of requests in the queue; $\mathrm{S}_{\mathrm{id}}$ - cost of costs associated with idle workers.

The probability of loading the dispatching service regardless of the structural scheme of the organization:

$$
p=\lambda_{a} \cdot\left(Z_{\text {serv }}+Z_{d}\right)
$$

Where $\lambda_{a}$ - the number of incoming applications to the dispatch service; $Z_{d}-$ time of transfer of the application from the dispatcher to the executor of works.

Regardless of the structural schemes considered, the dispatch service is staffed with the necessary number of workers of the required specialty for the most rapid elimination of possible malfunctions of the elements of the high-rise building.

\section{Results}

Three models of the organization of work of the dispatching service were considered. The first model is a single dispatch center for collecting and registering applications from the entire building, regardless of the functional purpose, dividing the engineering systems into zones vertically or horizontally (Figure 1). The processed applications are transferred to the brigades, who also carry out work at any point of the building. Such an arrangement is most optimal if there is one owner, tenant or one management company in the building. As a rule, this situation is not typical for high-rise buildings. 


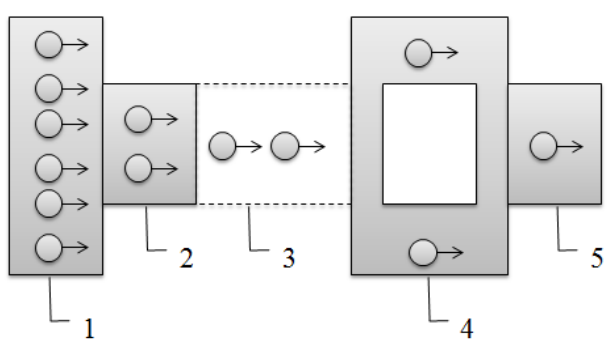

Fig. 1. The model of the organization of a single dispatch center with a common brigade service (D1): 1 - flow of incoming applications; 2 - reception and processing of applications by the dispatching service; 3 - order execution queue; 4 - application service; 5 - throughput of technical personnel.

Performance indicators are defined as for a queuing systems one-channel with an unlimited queue. Probability of downtime of technical specialists:

$$
P_{0}=1-p
$$

Average number of requests in the queue:

$$
n_{q}=\frac{p^{2}}{1-p}
$$

Average time of the application in the queue:

$$
Z_{q}=\frac{p^{2}}{\lambda_{a} \cdot(1-p)}
$$

Average time of the application in the system:

$$
Z_{\text {sist }}=\frac{1}{\lambda \cdot(1-p)}
$$

The second model is also a single dispatch center for the collection and registration of applications. However, processed applications are transferred to teams that have fixed service areas (Figure 2). The distribution of service areas can be carried out according to the functional purpose, height of the building, etc.

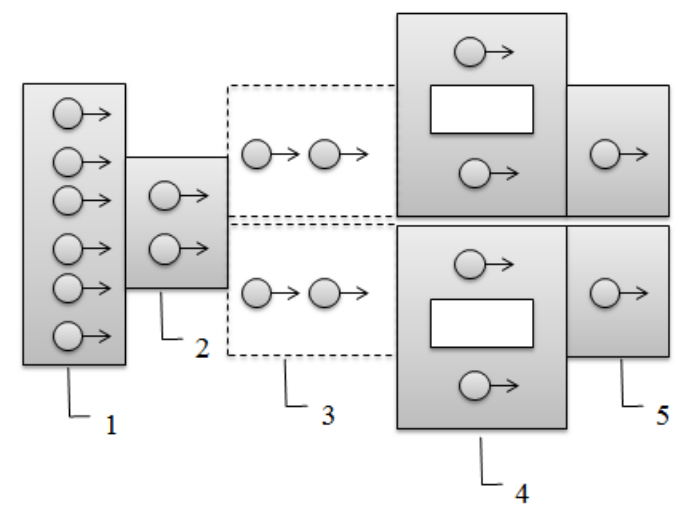

Fig. 2. The model of the organization of a single dispatch center with a specialized brigade service (D2).

This variant of the organization of work is advisable in the presence of different owners, different management companies in the same building. Then the organization of work of repair crews can be dealt with by each managing company separately. Performance 
indicators are defined as for a multi-channel queuing system with an unlimited queue. Probability of downtime of technical specialists:

$$
P_{0}=\left(1+p+\frac{p^{2}}{2 !}+\frac{p^{3}}{2 ! \cdot(2-p)}\right)^{-1}
$$

Average number of requests in the queue:

$$
n_{q}=\frac{p^{3}}{2 \cdot 2 ! \cdot\left(1-\frac{p}{2}\right)^{2}} \cdot P_{0}
$$

Average time of the application in the queue:

$$
Z_{q}=\frac{p^{2}}{\lambda_{a} \cdot 2 \cdot 2 ! \cdot\left(1-\frac{p}{2}\right)^{2}} \cdot P_{0}
$$

Average time of the application in the system:

$$
Z_{\text {sist }}=Z_{q}+\frac{1}{\lambda}
$$

The third model consists of several dispatch center accepting applications from fixed objects (premises, engineering systems, equipment, owners, etc.) and transferring them to strictly repaired repair teams (Fig. 3).

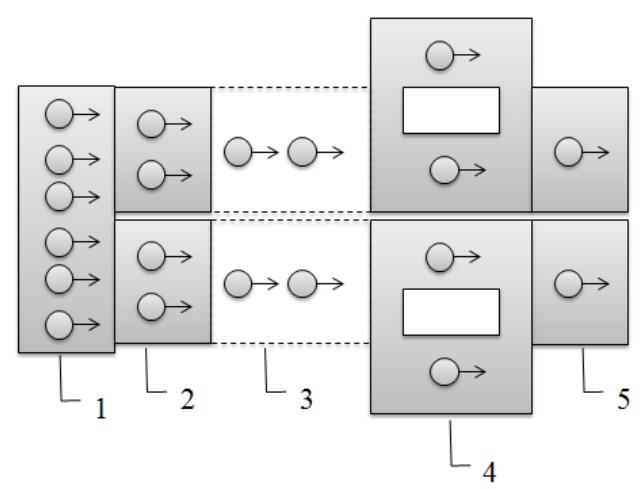

Fig. 3. The model of the organization of several dispatch centers with specialized brigade service (D3).

Such an option for organization of work is expedient if it is necessary to provide the maximum level of reliability, but it is characterized by significant operating costs. Performance indicators are defined as for a single-channel queuing system with an unlimited queue using formulas (5-8).

With a decrease in the number of incoming orders to the dispatch center, up to $40-50 \%$ of the calculated value, the management company will incur losses (Figure 4). In further calculations, it is advisable to consider a decrease in the number of incoming orders to $60 \%$ of the calculated value as critical. 


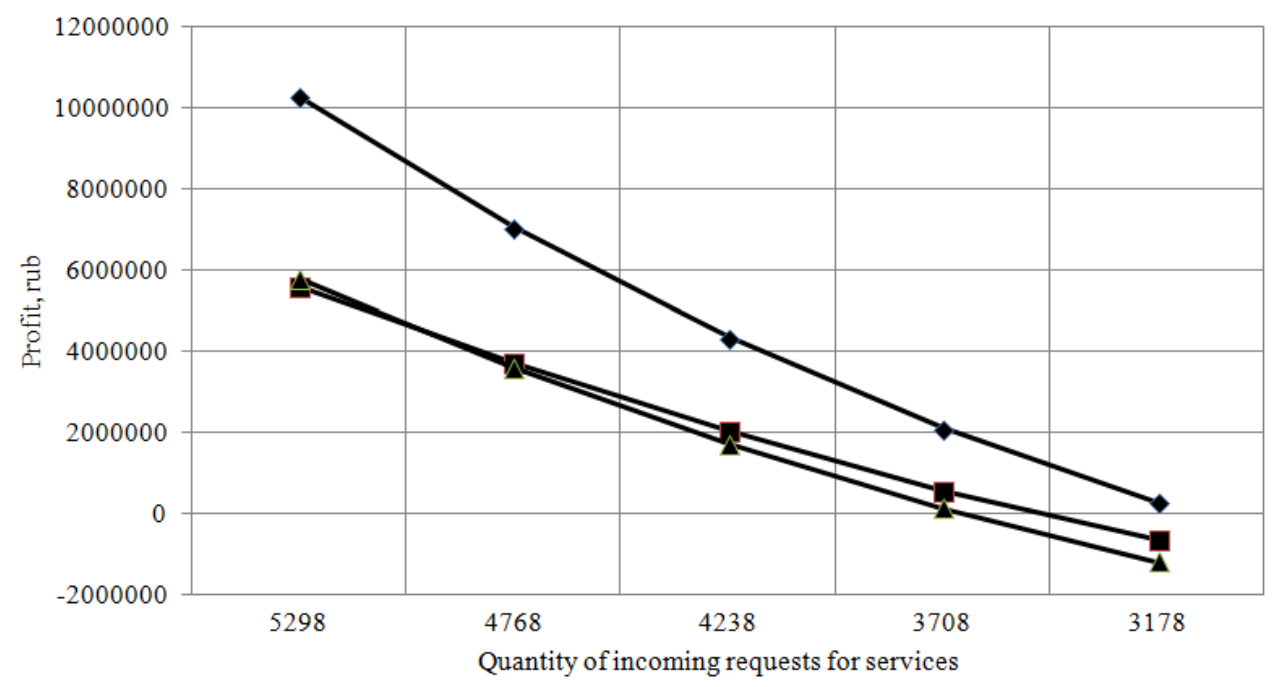

Fig. 4. Indicators of profit depending on the number of incoming applications.

Taking into account the maximum admissible value of the time of the application in the system equal to eight hours, all dispatch services are applicable (Figure 5).

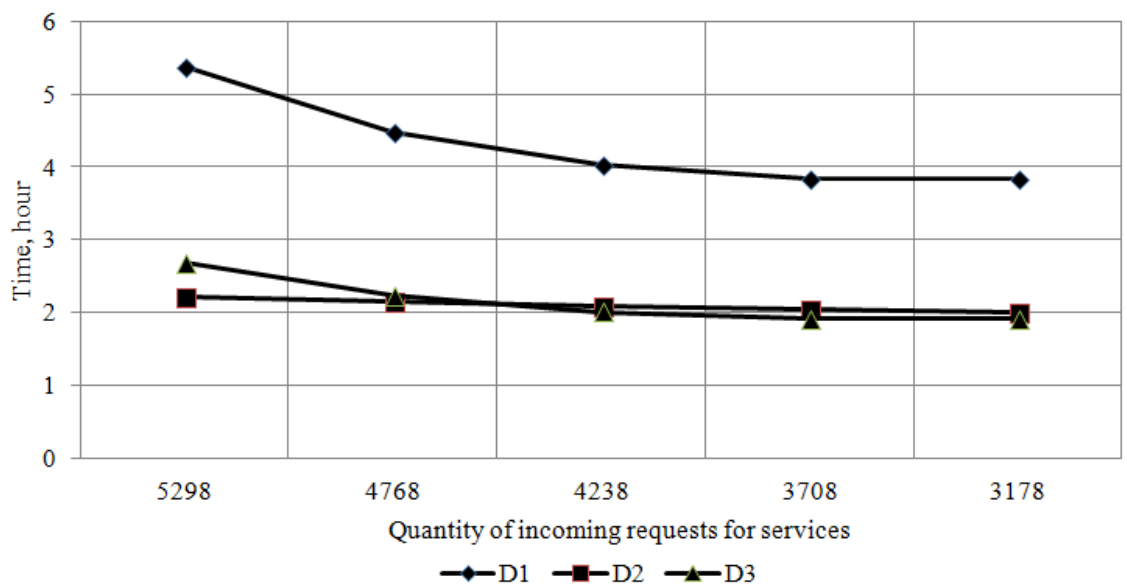

Fig. 5. Indicators of the time of application in the system depending on the number of incoming applications.

The profit indicator is the best when the normative intensity of the processing of applications by technical experts approaches the number of incoming applications to the control center as much as possible. With the increase in productivity, the costs associated with the idle time of specialists increase, and with a decrease, the costs associated with increasing the queue length and losses when the application is in the system are increased (Figure 6). 


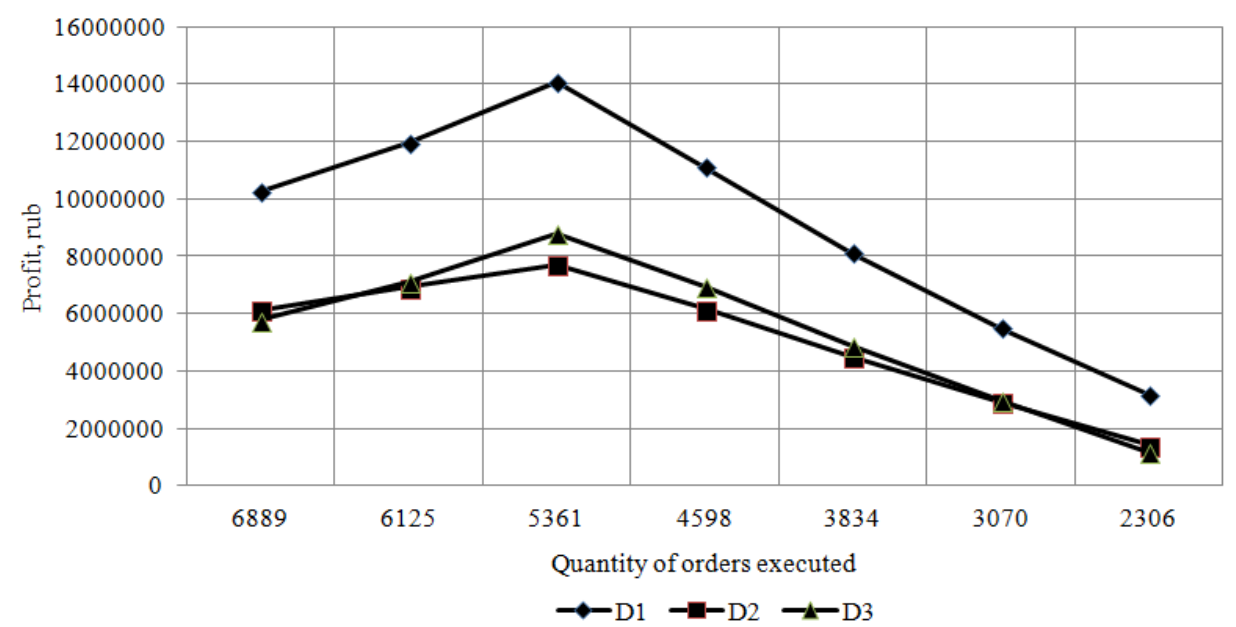

Fig. 6. Indicators of profit, depending on the intensity of work performed by technical specialists.

The time spent in the system is significantly increased in single-channel systems with a $10 \%$ or more reduction in performance (Figure 7).

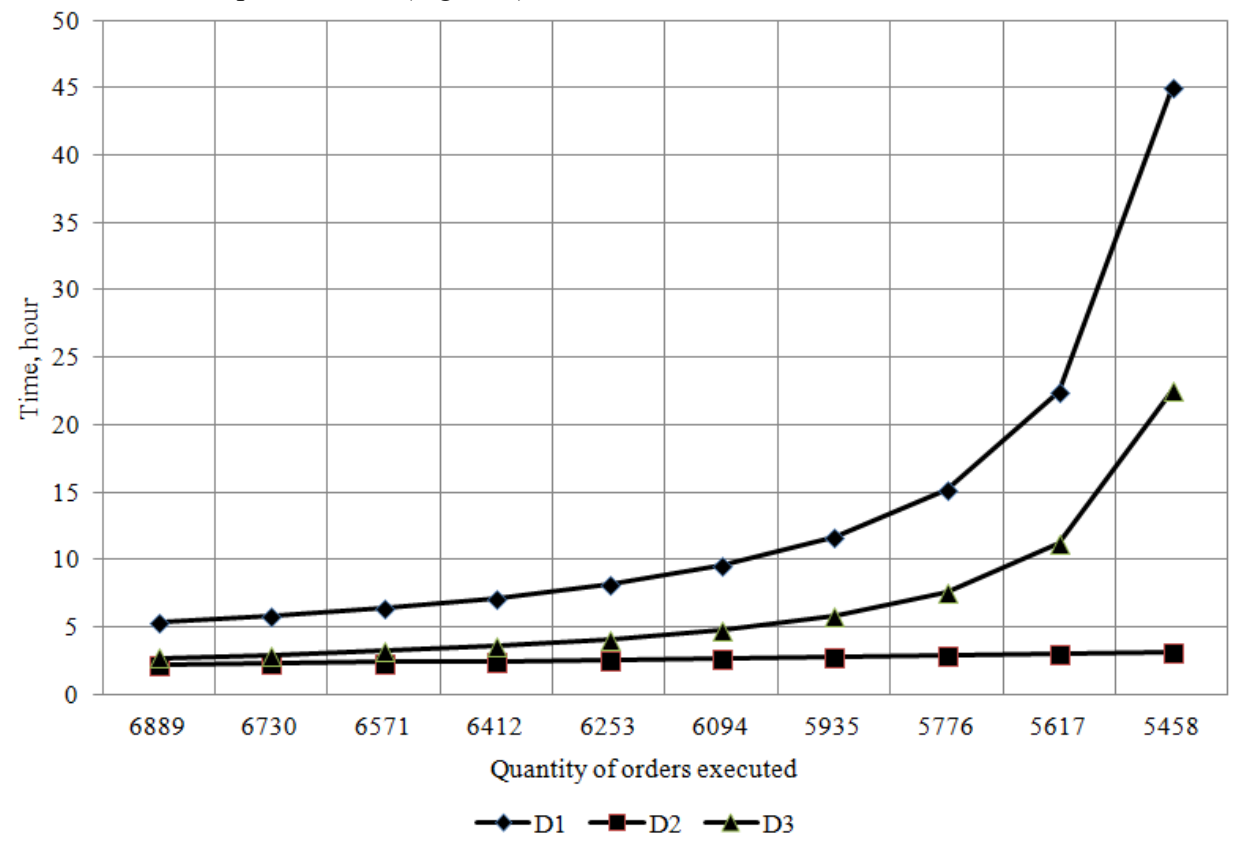

Fig. 7. Indicators of the time of application in the system, depending on the intensity of work performed by technical specialists.

\section{Discussion}

The carried out researches have allowed to define problem situations at the organization of work of dispatching service of a high-rise building. The novelty of the research is that analytically and graphically the dependences of the profit amount were revealed during the dispatching service operation from the costs of organization of the dispatch center, the cost of organizing the work of repair teams, the costs of materials for troubleshooting in 
engineering systems, the costs associated with the queue and the regulatory intensity execution of applications by technical specialists, as well as the time of finding the application on the network and the time of elimination of the failure from the normative intensity technical experts.

It was found that the maximum revenue is associated with the highest execution time of applications. In addition to the flow of incoming applications, it is necessary to optimize the performance of teams. The second and the third model (D2, D3) are close in terms of their performance, despite the different number of throughput channels.

The practical significance of the study is justified by the developed algorithm for making decisions on the selection of the most effective dispatching service scheme (Figure 8 ). The algorithm is designed to automate decision making, develop a computer program to help workers of exploitation services. The algorithm presents the initial data influencing the change in the efficiency indicators of the dispatching services, the calculated indicators and the decision-making mechanism.

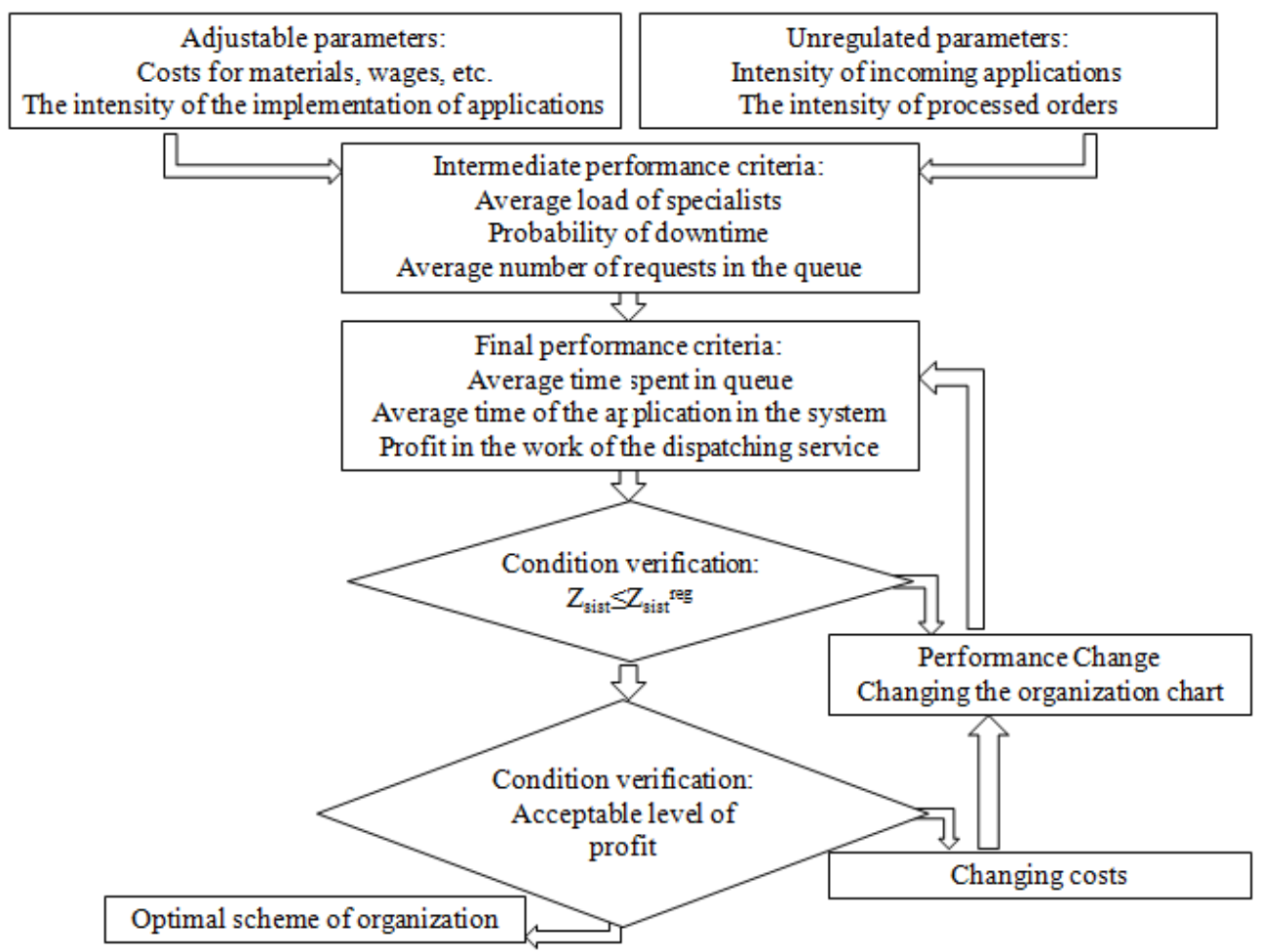

Fig. 8. Algorithm for choosing the optimal scheme for the organization of the dispatching service.

\section{Conclusions}

To solve the task set in the work, the following tasks were solved:

- the analysis of expediency of construction of high-rise buildings in conditions of existing city building is executed;

-the specifics of the organization of the dispatching service in the structure of the managing company of the high-rise building are analyzed;

-fulfilled a review of the main exploitation measures and their classification into two groups of work: constant and probabilistic; 
- proposed a time loss factor for technical and technological breaks, preparation of a specialist for the processing of an application, acceptance and storage of consumables in a warehouse, the elimination of several faults in one application, affecting the processing time of an application by a technical specialist;

-used the methodology used to calculate the performance indicators of the dispatching service based on the theory of mass service;

- dependencies of the influence of the changed indicators of the dispatching service on the time and profit criteria are established;

- developed an algorithm for making decisions on the selection of the optimal scheme for the organization of the dispatching service.

\section{References}

1. V.V. Aurov, Works of the Moscow Architectural Institute, 1, 185-187 (2015)

2. P.P. Zueva, Int. Conf. Actual problems of construction, ecology and energy conservation in Western Siberia, 3, 98-104 (2014)

3. P.P. Zueva, Architecture and construction of Moscow, 553, 5, $42-54$ (2010)

4. D.A. Efremyan, A.Yu. Sidorenko, T.O. Kondratenko 4. Science yesterday, today, tomorrow, 9 (43), 57-62 (2017)

5. URL: http://mingitau.livejournal.com/112278.html (2018)

6. M. Pecio, Bezpieczenstwo i Technika Pozarnicza, 42, 159-165 (2016)

7. S.Sh. Sairiddinov, Urban planning and architecture, 7, 2 (27), 38-47 (2017)

8. A.A. Raevskaya, A.O. Bykov, A.I. Platitsyna, World science: problems and innovations, 1, 161-163 (2017)

9. Yu.A. Matrosov, Construction Materials, 10, 90-92 (2005)

10. PM-2957 Recommendations for the operation of multifunctional high-rise buildings and complexes, Moscow (2006)

11. A.P. Kirpichnikov, D.B. Flax, K.N. Galyamova, Bulletin of Kazan Technological University, 19, 11, 122-125 (2016)

12. A.P. Kirpichnikov, D.B. Flax, Bulletin of Kazan Technological University, 17, 24, 242-245 (2014)

13. L.N. Polyakova, V.V. Karelin, V.M. Bure G.M. Hitrov, Bulletin of St. Petersburg University, 1, 75-82 (2015)

14. M.I. Busarev, A.P. Kirpichnikov, D.B. Flax, Bulletin of Kazan Technological University, 22, 155-161 (2011)

15. I.M. Yakimov, A.P. Kirpichnikov, G.R. Zainullina, Yu.G Isayeva, Z.T. Yakhina Bulletin of Kazan Technological University, 19, 5, 141-145 (2016)

16. S.B. Malkov, News of SFU. Technical science, 7 (42), 94-101 (2004)

17. I.N. Valeev, A.P. Kirpichnikov, Bulletin of Kazan Technological University, 4, 75-79 (2006)

18. A.P. Kirpichnikov, I.N. Valeev, Survey of Applied and Industrial Mathematics, 14, 5, 891-893 (2007)

19. Yu.E. Malashenko I.A. Nazarova, Informatics and Applications, 8, 1, 12-20 (2014)

20. T.V. Zakharova, Bulletin of Moscow University, 15, 4, 32-37 (2007)

21. E.V. Larkin, V.V. Kotov, A.N. Ivutin, A.N. Privalov, Journal of Computational and Engineering Mathematics, 3, 2, 14-24 (2016) 
22. G.D. Drozdov, Innovations, 11, 115-119 (2011)

23. A.N. Loshakov, Plumbing, Heating, Conditioning, 3 (147), 78-79 (2014)

24. M.E. Dement'eva, A.D. Vishnevetskiy Proceedings of Moscow State University of Civil Engineering, 2, 203-209 (2014)

25. A.G. Retivin, A.I. Pestryakov, K.A. Pavlychev, The Bulletin of the NGIEI, 4 (35), 107112 (2014)

26. Yu.K. Khabibullin, O.B. Barysheva, News of Kazan State University of Architecture and Civil Engineering, 2 (40), 198-205, (2017)

27. A.I.Frolov, Information systems and technologies, 1-4, 226-230 (2006) 